\title{
Renal disease in pregnancy
}

\author{
GEORGE WILLIAMS
}

From the Department of Pathology, Medical School, University of Manchester

Renal diseases may be of primary origin, or arise as manifestations of systemic disorders. In pregnancy, both their nature and incidence are subject to modification. A few, such as preeclampsia, are peculiar to it; others, which give rise to adverse metabolic effects, as in chronic renal failure, reduce fertility and have a correspondingly low incidence.

The physiological state of pregnancy significantly alters body homeostasis. Some of the changes affect the kidney and urinary tract directly (Sims, 1968; Berman, 1974); compared to the non-pregnant state there is a $50 \%$ increase in glomerular filtration rate and a $25 \%$ increase in renal plasma flow with appropriate lowerings of serum creatinine and urea levels. Glycosuria is more common and serum uric acid levels are raised. Urinary conducting pathways are also affected. By the end of the first trimester the renal pelvicalyces and ureters, particularly on the right side, show diminished peristalsis-an atonic state which persists late into pregnancy and may remain for several years, if not indefinitely (DureSmith, 1968). On a more general basis, but with important renal implications, is an increase in blood coagulability, a reflection of raised levels of several clotting factors and depressed fibrinolytic activity (Nilsson and Kullander, 1967; Rizza, 1970; Studd, 1973).

Awareness of these physiological changes is not only pertinent to a consideration of renal diseases in pregnancy but essential for the interpretation of clinico-pathological data of patients under investigation or treatment.

\section{Renal Infection in Pregnancy}

Pathogenic microorganisms may enter the kidney in infected emboli, but in pregnancy, retrograde spread from an infected focus lower down the urinary tract is much the more common route. Impaired contractility of the ureter, which may progress to atony, together with mechanical obstruction by a gravid uterus in women when standing, favour the multiplication and spread of bacteria, particularly in the latter half of pregnancy.

Infection may be confined to the renal pelvicalyces as a pyelitis or penetrate the kidney substance to produce a pyelonephritis. The latter, particularly in its more fulminating forms, is the most serious of urinary tract infective lesions which may complicate pregnancy. The benign end of this spectrum is represented by bacteriuria which may reach significant proportions (Asscher, 1974) but fail to produce overt clinical symptoms, a condition defined as asymptomatic bacteriuria. This topic requires brief consideration in relation to kidney infections as a whole. Bacteriuric patients often proceed to symptomatic infections during pregnancy but these can be substantially reduced by adequate antibiotic treatment (Kass, 1960; Whalley, 1967). Although a clearly recognized clinical entity with adverse implications in pregnancy, bacteriuria has no established histopathological basis. Fairley (1971) concluded that the source of infection in over $50 \%$ of cases was probably the renal pelvis. Others, including Kaitz (1965), Norden and Tuttle (1965) and Kincaid-Smith (1968), produced evidence of renal impairment or interference with the urinary outflow tract in approximately half of their bacteriuric patients.

Current concepts of bacteriuria have evolved against a background of variables-methods of urine collection and culture, criteria for assessing renal function and the socio-economic status of patients studied-have differed widely. Short-term studies are of limited value; long-term studies are few but indicate that the vast majority of patients with this disorder suffer no significant deterioration of renal function, reduction of kidney size, or hypertension over periods of up to seven years after delivery, in spite of recurrent infections (Bullen and Kincaid-Smith, 1971). The uncertainties of this condition will remain until more is known of its long-term effects, or until its morbid anatomical background is understood, although it is difficult to see how this could be attained in significant numbers of cases. Meantime, this potentially hazardous condition, which afflicts $3-5 \%$ of the female population as a whole, poses a particular threat to pregnancy in that $20 \%$ of women with bacteriuria in the early stages progress to acute pyelonephritis during that pregnancy (Asscher, 1974).

Acute pyelonephritis, on the other hand, has a 
well known morbid anatomical basis. Itcomplicates $1-2.5 \%$ of pregnancies with its highest incidence in the latter half or in the puerperium (Klempner et al, 1960). Of a wide range of causal organisms, Escherichia coli is the most common but enterococci, staphylococci, pseudomonas, and yeast-like fungi are recognized potential pathogens. Clinically, it may present with acute fever, lumbar pain, dysuria with frequency, haematuria, pyuria and bacteriuria, but more often, more insidiously, and sometimes may be symptomless. Repeated urine examinations for white cells and organisms are essential in that both may be present intermittently, or even not at all, in latent infections. In this circumstance, pathological increases of white cell excretion rates may be evoked by injections of pyrogen or prednisolone (Little and De Wardener, 1962; Katz et al, 1962) or iron sorbitol citric acid (Devi et al, 1967).

\section{PATHOLOGY}

The pathological changes of acute pyelonephritis involve a sequence of infection and inflammation of the pelvicalyces and their extension into the kidney substance along collecting ducts and nephrons. Radiating zones of dense leucocytic infiltration (fig 1) involve both interstitium and tubules which contain pus casts, red cells and microorganisms (fig 2). Tissue breakdown with extension and coalescence of inflammatory areas may produce abscesses (fig 3) in both cortex and medulla. Vascular components, including glomeruli, tend to resist the lytic process but may occasionally be thrombosed. The patchy nature of the lesions results in alternating areas of relatively normal and abnormal tissue which accounts for the mottled, often haemorrhagic appearances which characterize the gross renal appearances in this disorder (fig 4).

In its fulminating bilateral form, acute pyelonephritis may cause renal failure (Kleeman et al, 1960). Fortunately in pregnancy it very rarely attains this extent or severity. Milder degrees of pyelonephritis are, however, not rare and tend to run a relapsing, chronic course (Pinkerton et al, 1961). In common with bacteriuria they have important implications for the health of both mother and fetus.

\section{Acute Renal Failure}

Acute renal failure may be prerenal, post-renal or renal (parenchymal) in origin (Brun and Olsen, $1968)$. It has a low incidence in pregnancy $(1: 1500$ 1:5000) with a bimodal distribution: one frequency peak at 15 weeks related primarily to septic abortion, and the other at 35 to 40 weeks, usually a consequence of abruptio placentae (Harkins et al, 1974). Each of these clinical states has a pathological basis, the

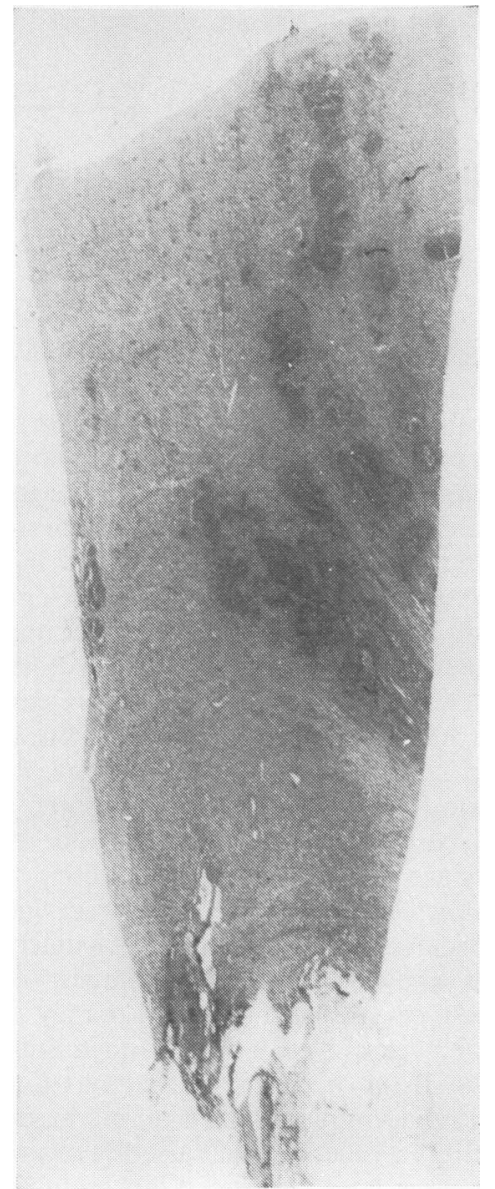

Fig 1 Acute pyelonephritis showing patchy distribution of (dark) areas of inflammation within renal tissue. $H \& E \times 4$.

former as acute tubular necrosis, the latter as renal cortical necrosis.

\section{Acute Tubular Necrosis}

Two factors contribute to this lesion: (1) the effect of toxins on sensitive tubular epithelium, and (2) ischaemia, which may also complicate shock in postpartum haemorrhage (Murray-Jones, 1954).

Clinically, this disorder follows a phasic pattern (Bull et al, 1950) of (1) severe shock and circulatory collapse; (2) oliguria or anuria for several days or weeks; (3) an early diuretic phase with marked increase of urinary output, although urea and creatinine retention and electrolyte disturbance still apply; (4) a late diuretic phase with improvement in 


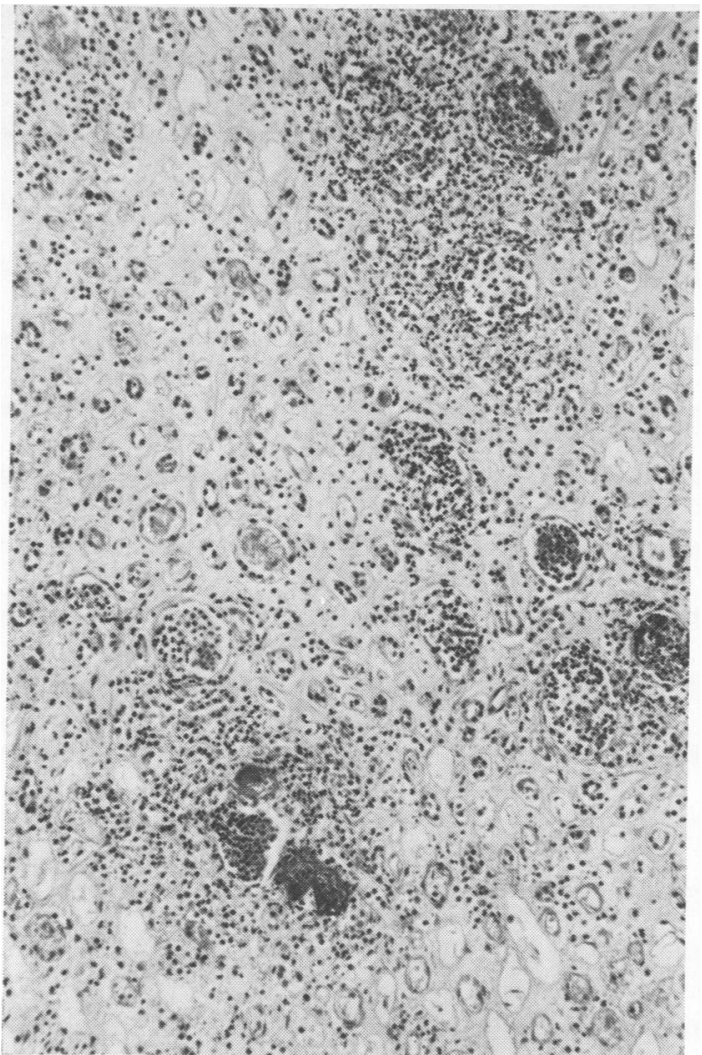

Fig 2

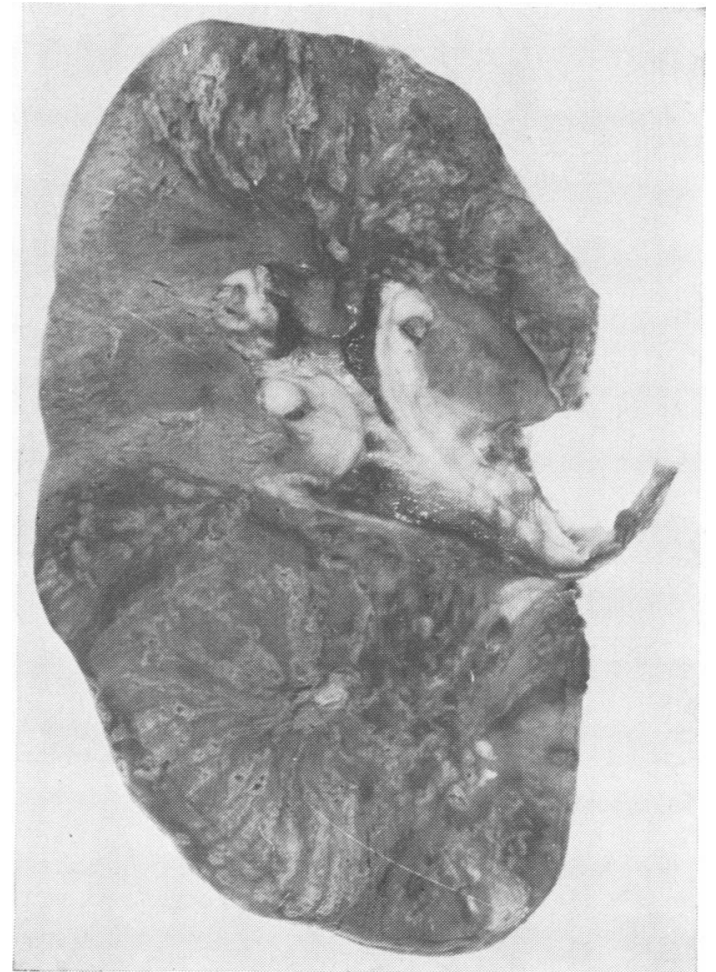

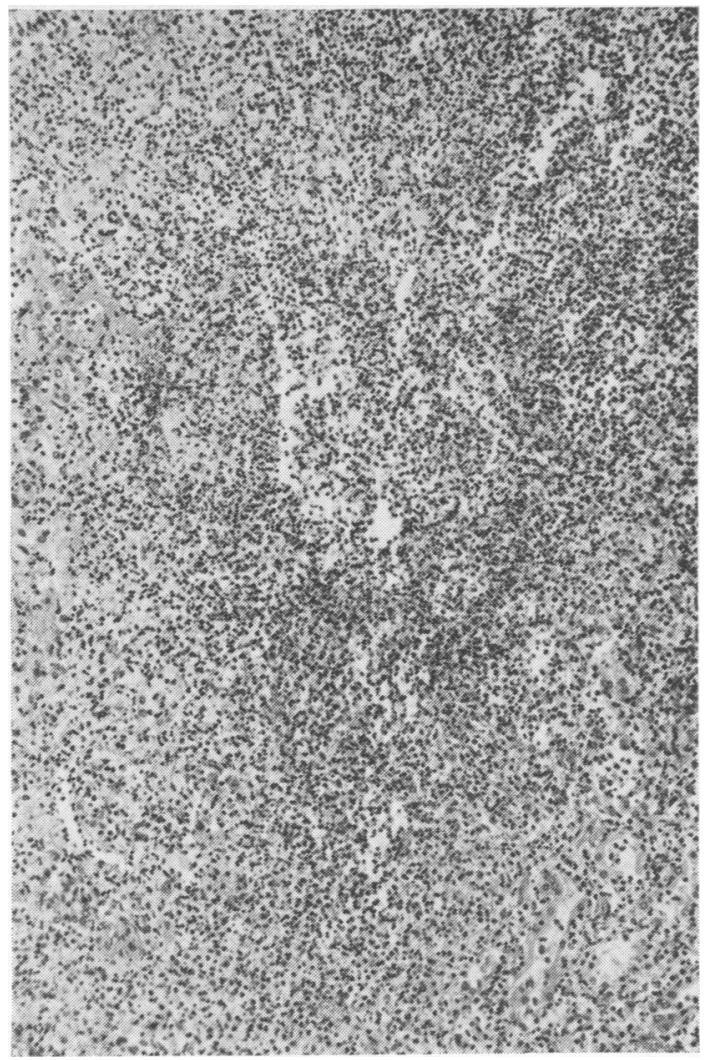

Fig 3

Fig 2 Infected tubules contain granular casts, red blood cells and microorganisms. $H \& E \times 120$.

Fig 3 Early abscess formation with lysis of renal tissue and dense leucocyte infiltration. $H \& E \times 120$.

Fig 4 Hemisected kidney extensively involved with acute (suppurative) pyelonephritis. Both renal poles show abscesses and radiating pathways of infection. Renal papillae within the pelvis are necrotic. 
renal function, restoration of glomerular filtration and return to normal blood urea levels.

In structural terms, the major damage falls on the distal, rather than proximal, tubules, creating the so-called 'boundary zone' lesion. Within the first few days, very little by way of change may be seen. Tubules, lined with a low cuboidal epithelium, may be dilated and separated from each other by interstitial oedema (fig 5). Later, in areas of tubular damage there is a variable, interstitial inflammatory infiltration. This is followed in most instances by epithelial regeneration (fig 6). The loops of Henle do not escape but fare better than distal tubules. Lower nephrons contain pigment or granular casts, and a range of nucleated cells, probably of haematogenous origin (Baker, 1958) may occupy the vasa recta (fig 7). Glomeruli, in common with the renal vasculature, usually escape overt injury. The outcome of this condition is closely linked to the nature

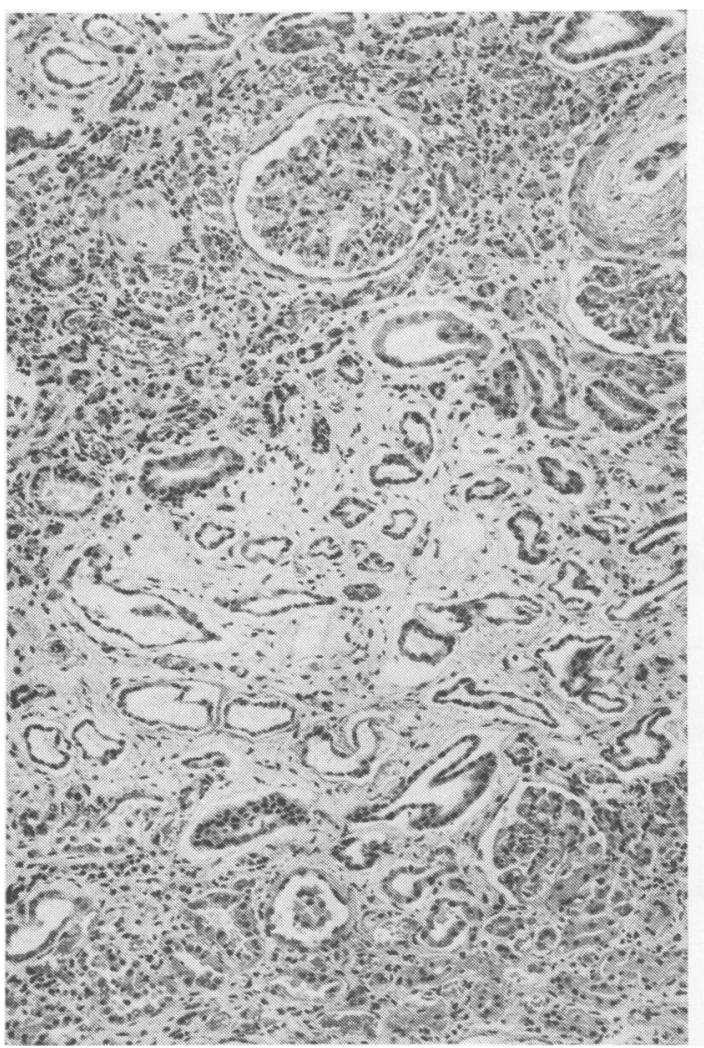

Fig 5 and severity of tubular injury. These were assessed in dissected nephrons by Oliver et al (1951) who showed that both nephrotoxic and tubulorhectic injuries may contribute. The former applied when damage was restricted to the lining tubular epithelium. As such and if not too extensive, it is capable of repair. Repair is marked by mitotic activity and cytoplasmic basophilia of regenerating epithelium, with restoration of tubular lining. On the other hand, tubulorhexis denotes a severe lesion in which supporting basement membranes are destroyed focally. Urine or cast content leaking into the interstitium may provoke a granulomatous inflammation (fig 8) and regenerating tubular epithelium, lacking continuity of support is unable to re-establish tubular integrity.

There are relatively few accounts of this condition in the literature relating specifically to pregnancy although Loughridge et al (1960) recorded a $22 \%$

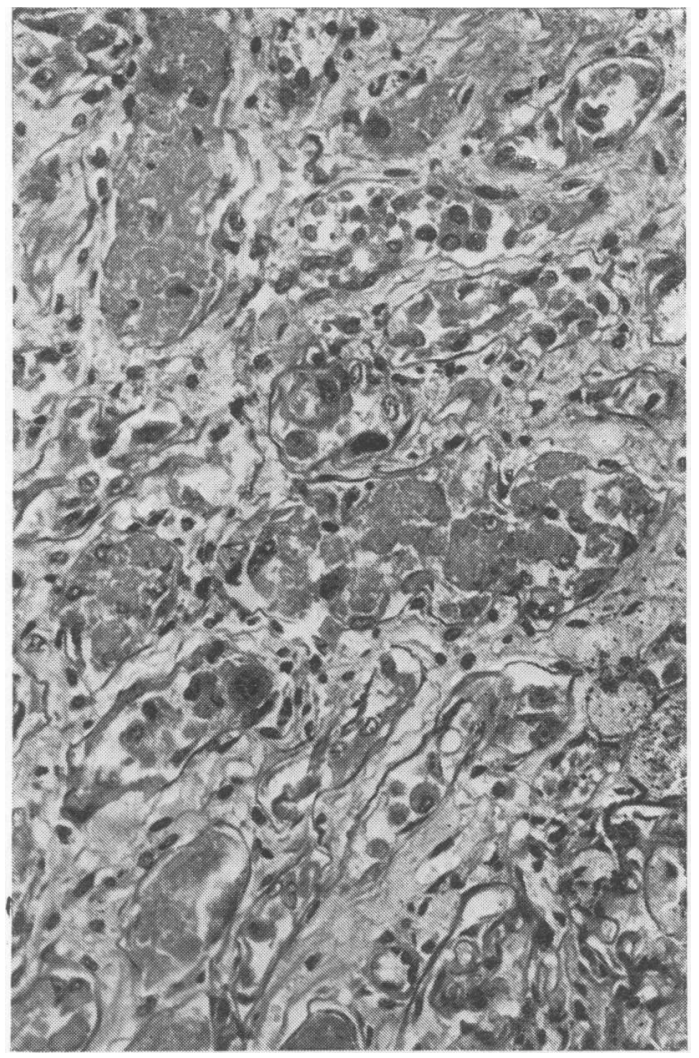

Fig 6

Fig 5 Early stage of acute tubular necrosis: renal tubules are dilated and separated by oedema. $H \& E \times 120$.

Fig 6 Regeneration following acute necrosis: tubular epithelium contains hyperchromatic nuclei with occasional mitoses; surrounding epithelium is basophilic. $H \& E \times 320$. 


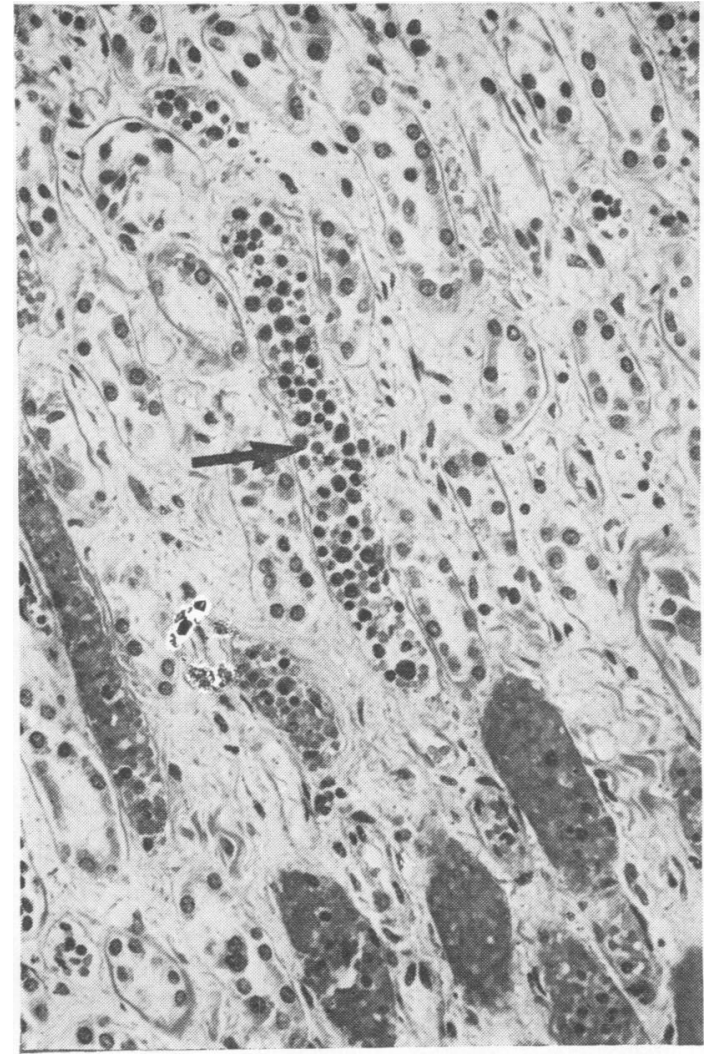

Fig 7 Vasa recta contain aggregates of nucleated (haematogenous) cells. $H \& E \times 270$.

mortality in 36 medical and obstetrical cases, half the fatalities occurring during the oliguric phase. Lowe (1952) described a series of 40 patients with acute tubular necrosis from various causes of whom 26 recovered; 14 of these (including four patients who had had an abortion) enjoyed good health despite reduced renal function. At long-term follow up one had completed a successful pregnancy three years after her acute episode; two others (who failed to attend follow up) had also recorded successful pregnancies.

\section{Bilateral Cortical Necrosis}

According to Ober et al (1956) about $80 \%$ of all cases of this disease arise as a complication of uteroplacental apoplexy, although the majority of patients who develop placental abruption fortunately escape this serious renal lesion. According to Sheehan and Moore (1952) its incidence rises with parity, $19 \%$ affecting primiparae and $49 \%$ occurring in the fifth

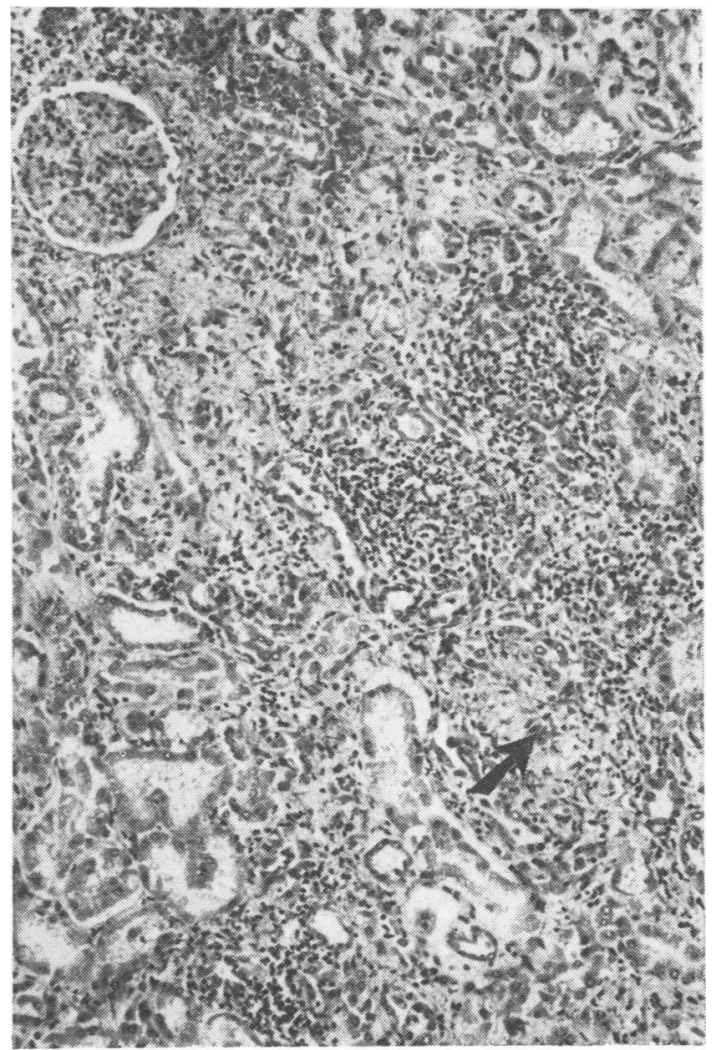

Fig 8 Interstitial granulomatous response (arrow) to tubular content following tubal rupture. $H \& E \times 120$.

or subsequent pregnancies of multiparae. Woods and Williams (1971), on the other hand, found no frequency relation to age or parity but rather to the number of weeks of gestation.

Although primarily associated with placental abruption, bilateral cortical necrosis may complicate preeclampsia or eclampsia or other obstetrical disorders (Burt and Kearns, 1953), including septic abortion.

The pathogenesis of this condition is debatable. Sheehan and Moore (1952) postulated an initial spasm at the glomerular level followed by restitution of the circulation, which, if not too long delayed and then continuous, limited the damage to the tubules. Return of vasospasm at the interlobular arterial level for several hours, with peripheral ischaemic damage, promoted thrombosis in necrosed arteries, permanent arrest of the circulation and coagulation necrosis of the cortical substance. Other authors place a different interpretation on its development. Thompson et al (1972) believe that the renal lesions which complicate toxaemia and abruptio placentae 
may share a common pathogenic denominator, viz, a hypercoagulable state based on differing rates of release of placental thromboplastin-slow in eclampsia, but massive in abruptio placentae. Others, however, have failed to detect significant evidence of disseminated intravascular coagulation in cortical necrosis (Straub et al, 1966), and Kleinknecht et al (1973) found that toxaemia rarely preceded it. McKay et al (1953) have repeatedly emphasized the importance of a Schwartzman-like reaction in the causation of bilateral cortical necrosis, particularly in pregnancy which has a 'sensitizing' effect for Gramnegative toxins.

Whilst the precise pathogenesis of bilateral cortical necrosis remains debatable and is probably multifactorial, there is general agreement that ischaemia is the ultimate causal mechanism (Wells et al, 1960).

\section{PATHOLOGY OF RENAL CORTICAL} NECROSIS

The studies of Sheehan and Moore in 1952 (to which readers are referred for details) form the basis of our understanding of this condition in histopathological terms. These authors described the renal lesions in increasing magnitude as focal, minor, patchy and gross.

Focal lesions comprised scattered necroses up to $0.5 \mathrm{~mm}$ in diameter; minor forms occurred as $2-3 \mathrm{~mm}$ lesions mainly in the outer cortex. Patchy forms involved necrosis of up to two-thirds of cortical tissue whilst the most extensive gross form signified almost total cortical destruction, only occasional juxtamedullary or subcapsular nephrons surviving. Thus Sheehan and Moore emphasized that cortical necrosis is by no means a uniformly fatal condition as is sometimes believed, and that focal grades are compatible with maternal recovery although fetal mortality is $100 \%$.

Regardless of its extent, the lesion is essentially a coagulative necrosis of both vascular and tubular tissues in the ischaemic areas (fig 9). These areas are demarcated, in time, from viable tissue by a zone of inflammatory cell infiltration. Gross appearances, particularly of severe forms, are characteristic, the swollen pale cortices contrasting with adjacent haemorrhagic or congested viable tissue (fig 10). According to Kleinknecht et al (1973) renal biopsy, selective arteriography and haemodynamic measurements are very useful in assessing the severity of the condition and in predicting recovery which can now be expected in all cases of partial cortical necrosis. In their experience, about $50 \%$ of survivors did not require chronic haemodialysis; in the other $50 \%$, renal function deteriorated to the point of requiring dialysis or renal transplantation.

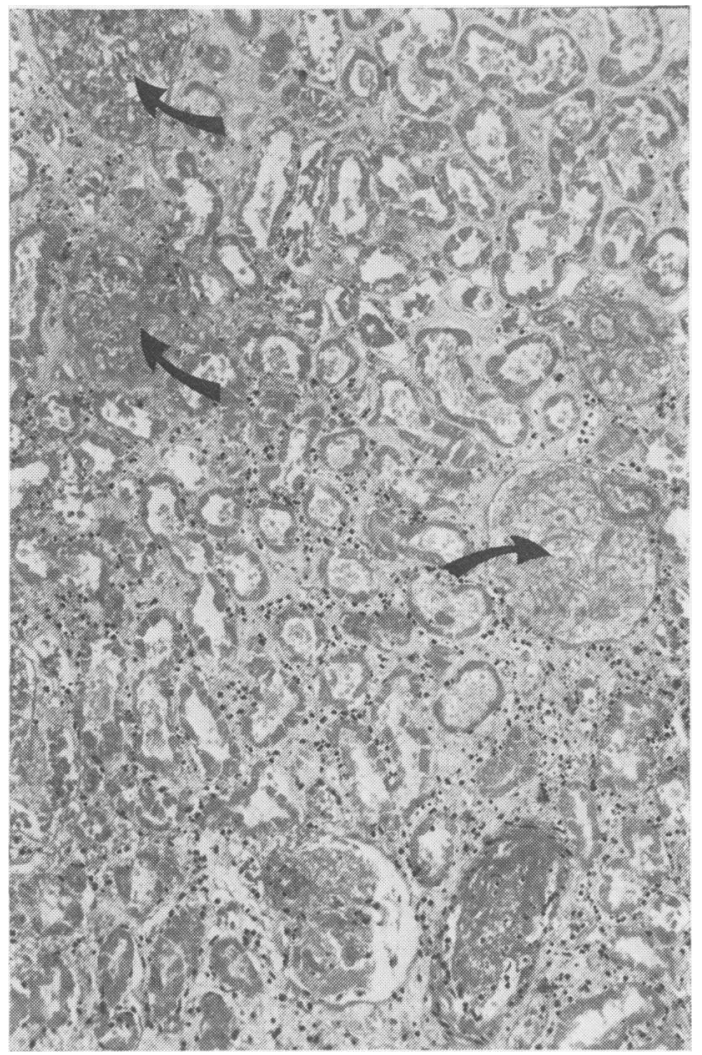

Fig 9 Renal cortical necrosis: glomeruli (arrows) and adjacent tubules are necrotic and vessel contains thrombus. There is a limited vital reaction in relation to damaged tubules. $H \& E \times 120$.

\section{Postpartum Renal Failure}

This rare syndrome is characterized by renal failure shortly after delivery or during the ensuing three months. The preceding pregnancy is, as a rule, normal and the onset of the oliguria is both sudden and unexpected. To date, probably no more than 30 cases have been described, including those by Robson et al (1968), Wagoner et al (1968) and Epstein and Scully (Massachusetts General Hospital, 1973). Patients are usually normotensive at the time of onset which may be marked by an influenza-like illness, but hypertension often follows, along with thrombocytopaenia and a haemolytic anaemia. The disease runs a rapid course and most patients so far encountered have died from a combination of kidney and heart failure. Two of the four patients reported by Finkelstein et al (1974), however, survived.

Clinicopathological CHANGES

The principal lesion is a thrombotic microangio- 


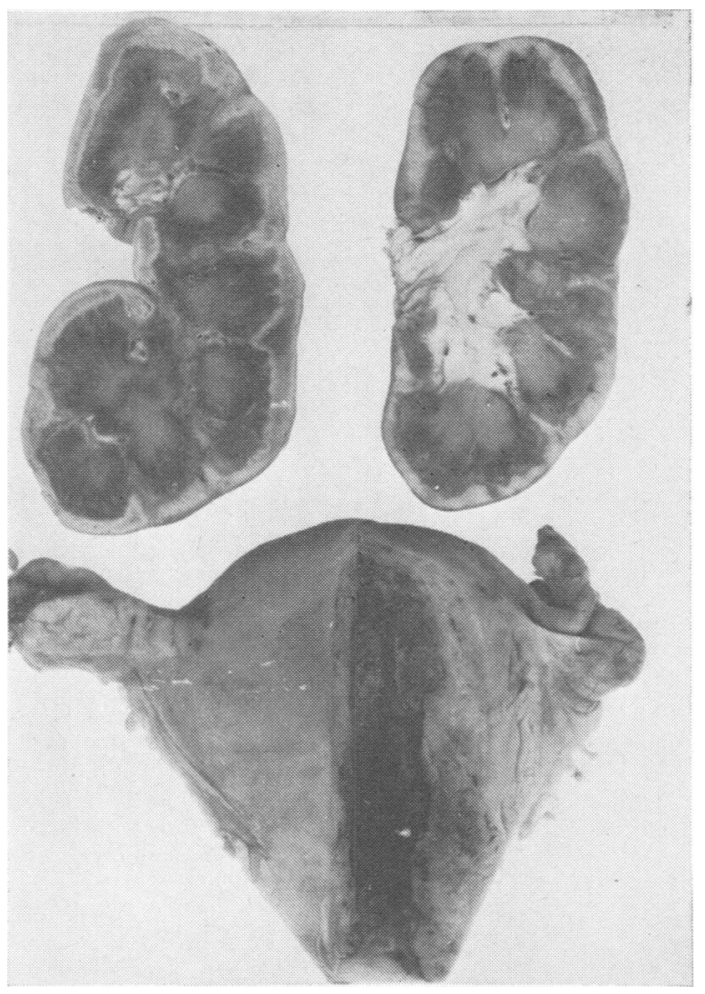

Fig 10 Gross appearances in renal cortical necrosis. Necrotic cortices contrast with congested medullae. The uterus shows a severe endometritis, the result of septic abortion.

pathy involving glomerular capillaries and adjacent arterioles (fig 11). Glomeruli are hypercellular, relatively bloodless and of globular outline; capillary basement membranes may show fibrinoid change associated with luminal thrombosis. The intima of arterioles and interlobular arteries is concentrically swollen and oedematous (figs 12 and 13). Adjacent tubules may be dilated and show focal epithelial regeneration, presumably in response to ischaemic damage.

Electron microscopy confirms an increase of mesangial cells and matrix with reduction in calibre of capillary lumina (fig 14). Capillary endothelium is elevated from its supporting basement membrane by a floccular infiltrate which incorporates polymorph leucocytes (fig 15). Immunofluorescent studies with appropriate antisera have disclosed glomerular deposition of complement and localizing IgG (Churg et al, 1970; Rosenmann et al, 1969) although Williams and Hughes (1974) found evidence of fibrin deposition only.
The nature of this condition is unknown. In structural terms it has features in common with the haemolytic uraemic syndrome-severe eclampsia, thrombotic thrombocytopaenic purpura and scleroderma-but its mode and time of onset in relation to pregnancy, poor prognosis and the restricted distribution of its lesions distinguish it from these conditions. It also embodies features of the Schwartzman reaction and of experimentally induced disseminated intravascular coagulation disease. From the clinical viewpoint it presents as acute oliguric renal failure for which anticoagulation would seem a rational treatment. Heparin would seem to have benefited some patients but is not the complete answer to this complex and distressing syndrome (Luke et al, 1970).

\section{Pregnancy and Glomerular Disease}

Acute primary glomerular disease rarely coincides

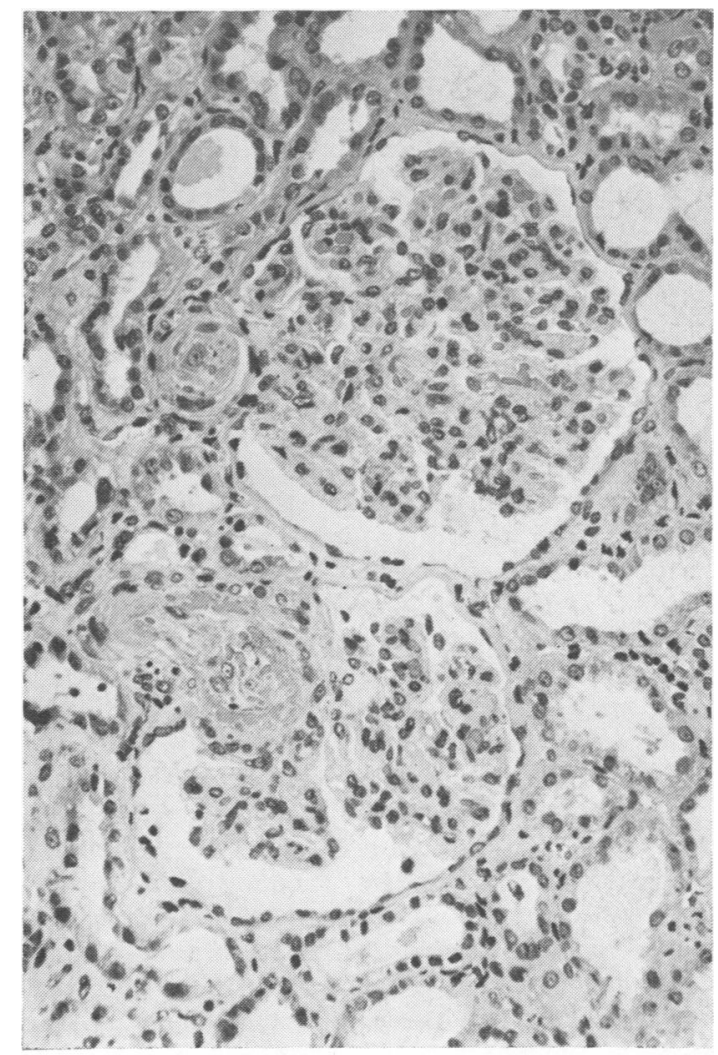

Fig 11 Postpartum renal failure: glomeruli have a globular outline and show increased mesangial cellularity. Adjacent arterioles are necrosed and thrombosed. $H \& E \times 250$. 


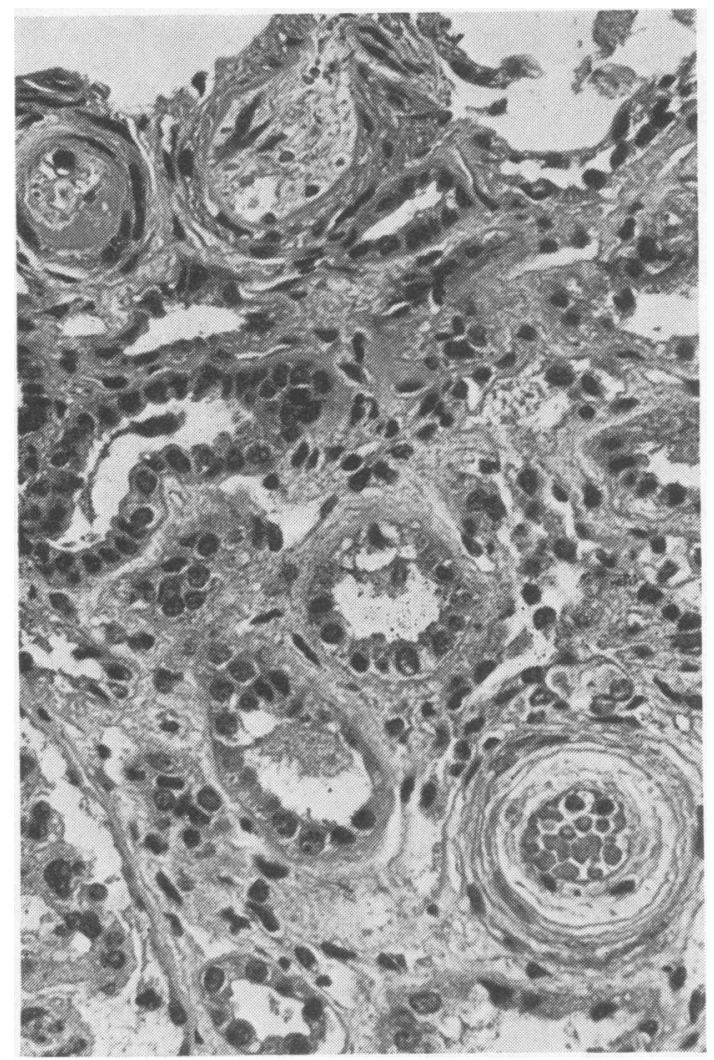

Fig 12

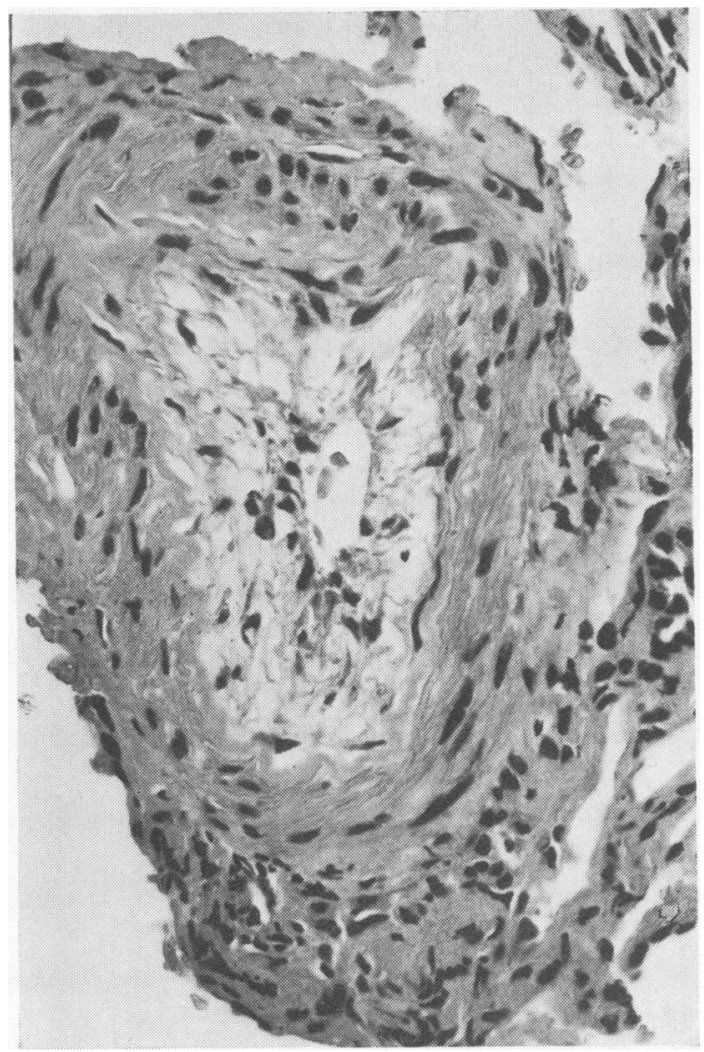

Fig 13

Figs 12 and 13 Intima of arterioles (12) and inter lobular arteries (13) show concentric swelling and oedema. $\times 350$.

with pregnancy. Barnes (1970) from available records of 39 patients found it associated with a fetal salvage of only $43.6 \%$ and a maternal mortality of $20.5 \%$ during pregnancy but made it clear that such statistics would doubtless be improved with modern treatment. Self-limited glomerular disease preceding pregnancy, has, however, noadverse effects(Tillman, 1951; Felding, 1968).

Chronic glomerular diseases, mainly on account of their diverse pathogenesis, have a less clear-cut relationship to pregnancy. Some are more progressive than others, their courses often punctuated by remissions and relapses. Proteinuria, established before pregnancy, is liable to worsen during it, mainly on account of an increased glomerular filtration rate and this, augmented by salt and water retention, may produce a full nephrotic syndrome. However, assuming the oedema is controlled adequately by diuretics and that neither hypertension nor renal failure supervene, the outlook for both mother and fetus is good. Several studies lend support to this view. Studd and Blainey (1969) recorded only two infant deaths in 31 pregnancies in nephrotic mothers; Johnston et al (1963) studied 29 pregnancies in 10 patients with nephrosis (in five cases uncomplicated and in five cases complicated); the uncomplicated group registered 11 live births from 12 pregnancies whereas in 17 pregnancies occurring in the complicated group, termination was required in six instances, and there were two miscarriages and only nine successful deliveries. Blainey and Studd (1971) in a 10-year follow up of 23 nephrotic patients involving 35 pregnancies recorded 33 normal deliveries although infant weights were reduced relative to their maturities. Only two mothers with severe proliferative glomerulonephritis showed serious deterioration of renal function requiring dialysis or transplantation. Comparably favourable results were recorded by Strauch and Hayslett (1974) in a study of 41 pregnancies in 25 patients whose renal diseases had been defined by renal biopsy. Our experience in Manchester (shortly to be published), 


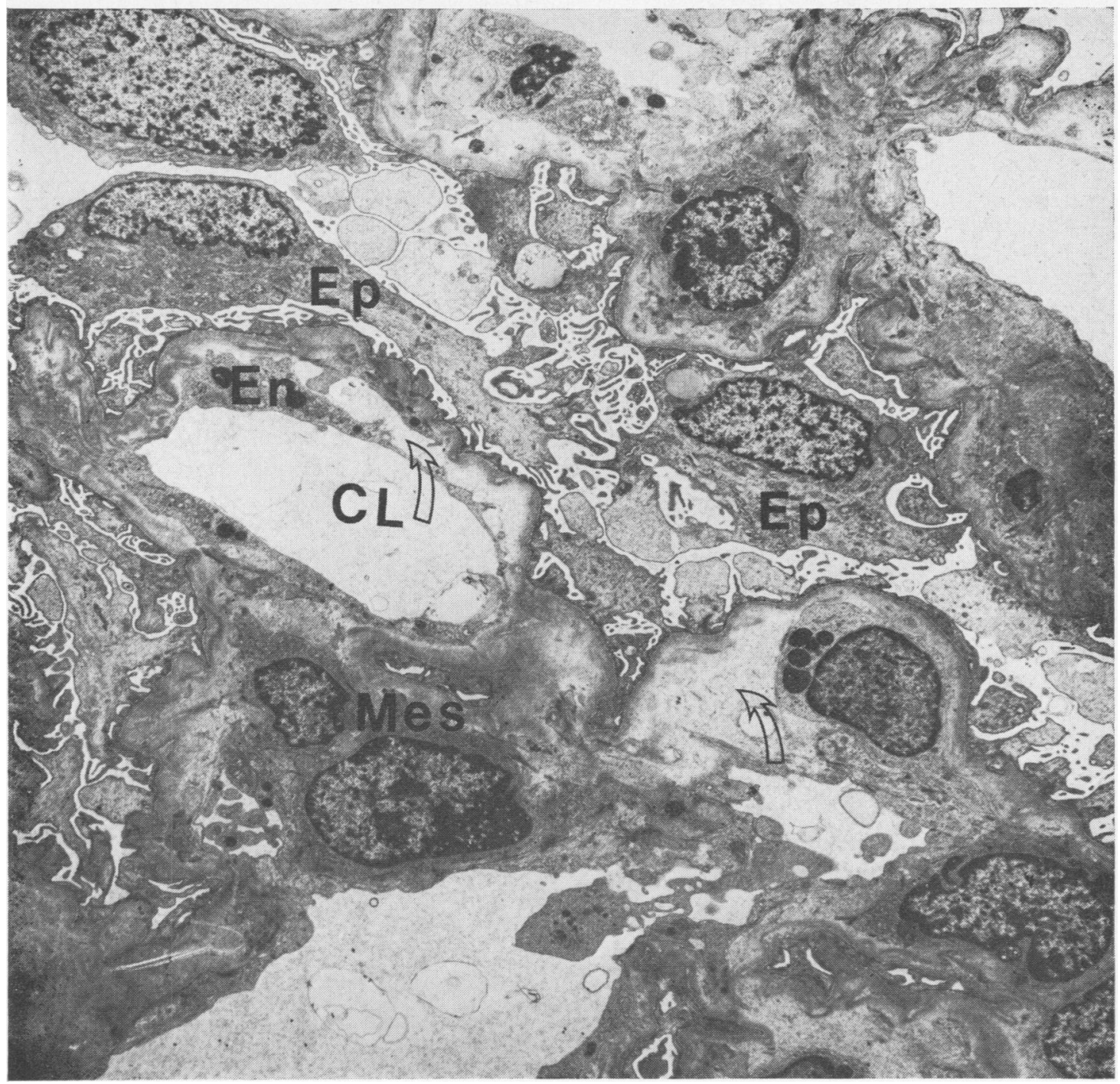

Fig 14

Figs 14 and 15 Glomerular basement membranes are convoluted. Epithelial cells (Ep) show prominent surface microvilli and irregular loss of foot processes. Capillary lumina $(\mathrm{Cl})$ are narrowed and lining endothelium (En) is separated from basement membrane by floccular material (open arrows) which incorporates polymorphonuclear leucocytes $(\mathrm{Pml})$, and cytoplasm (closed arrows) of probable mesangial cell (Mes) origin. EM $\times 6250$.

involving 20 patients and 32 pregnancies, follows a similar pattern.

Rarely, nephrosis may present for the first time during pregnancy. Weisman et al (1973) described six cases involving primigravidae. Renal biopsies taken at Caesarean section or percutaneously after delivery disclosed various glomerulopathies including preeclampsia - a rare cause of nephrosis. One fetal death ensued, but follow up of four of these patients disclosed improvement of renal function and several additional successful pregnancies.

A transient nephrotic syndrome has also been described in pregnancy by Schreiner (1963) and by Haslam and Wallace (1975) in New Zealand. It occurs mainly around the 31 st week and in both series $50 \%$ of patients were primigravidae. Hyper- 


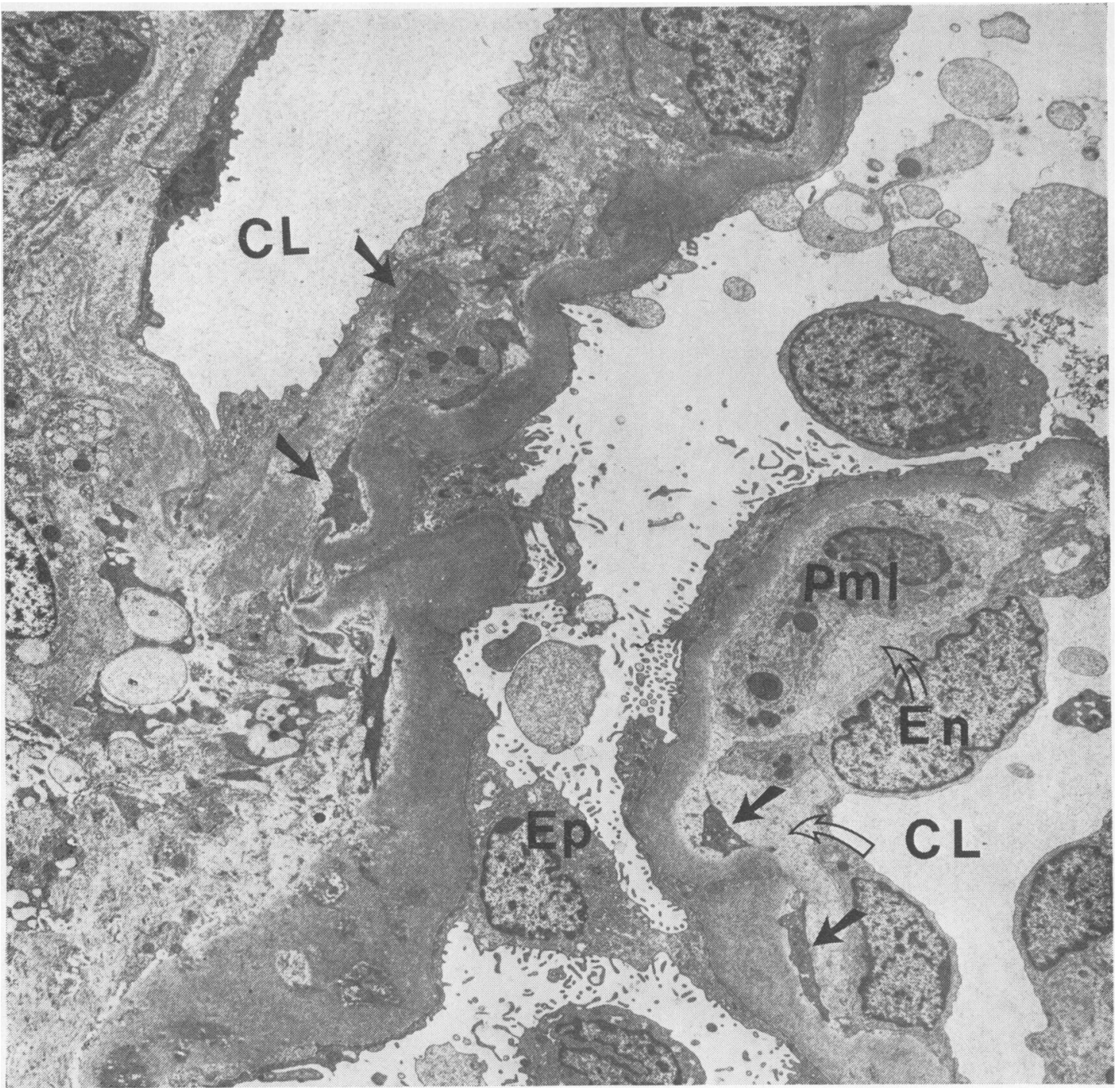

Fig 15 Another view of the EM shown in fig 14 of the convoluted glomerular basement membranes.

tension was a common complication, and in the New Zealand series eclamptic fits affected three patients. Overall fetal loss through intermediate and perinatal mortality was $41 \%$, the highest mortality being associated with an earlier onset of the syndrome. Hitherto, very few patients with this syndrome have been subjected to renal biopsy; both pathogenesis and aetiology are unknown.

SYSTEMIC LUPUS ERYTHEMATOSUS (SLE)

Glomerulopathies form an important aspect of several systemic diseases of which SLE is one of the more important. About $50 \%$ of patients with this disease experience renal involvement in a wide variety of forms which may range from a focal proliferative glomerulonephritis to a more indolent and diffuse thickening of glomerular basement membranes. This variety of glomerular involvement, together with changing treatment over the years, accounts for some of the controversy which surrounds its relationship to pregnancy. Donaldson (1952) in the earliest review (limited to eight patients) deduced that pregnancy had no effect on maternal SLE and that the disease did not influence fetal 
outcome. Ellis and Bereston (1952) agreed in terms of maternal disease but reported a $30 \%$ fetal wastage. Over the years several studies have followed, their extent increasing as more cases were reported (Friedman and Rutherford, 1956; Donaldson and De Alvarez, 1962; Estes and Larson, 1965; McGee and Makowski, 1970). In this context the prospective studies of the Chicago group (Garsenstein et al, 1962) are particularly informative in that they represent the most closely 'controlled' series yet reported. These authors studied the interrelationship of pregnancy and SLE in 21 patients involving 33 pregnancies. Seventeen pregnancies went to full term and produced 17 live infants; seven abortions, mainly spontaneous, occurred in the first 20 weeks of pregnancy, and from eight which terminated in the second half of gestation only two infants survived. There were four postpartum maternal deaths. They also investigated the effects of pregnancy on SLE by recording the exacerbations of disease (per 100 patient weeks at risk) over five periods of time, viz, 32 weeks before pregnancy, the first and second 20 weeks of pregnancy, eight weeks after delivery and 32 weeks thereafter. They found that exacerbations occurred with equal frequency during the two 32week periods (before and after pregnancy), that their frequency was twice that level in the latter half of pregnancy, four times as high in the first half and eight times as common in the immediate postpartum period.

In the light of published evidence, few generalizations concerning SLE and pregnancy can be regarded as accurate. On the whole it would seem that pregnancy does not adversely affect the nephritis of SLE although patients with active renal disease are more vulnerable. The main risk is that of postpartum exacerbation but there is also evidence that bold steroid and immunosuppressant therapy can, at least in the short term, stabilize the maternal disease and improve fetal prospects (McGee and Makowski, 1970; Jewett, 1972; Sharon et al, 1974).

Of allied systemic disorders, scleroderma is rarely associated with pregnancy. According to Karlen and Cook (1974) a total of 63 cases (including their own) have been reported, of which only three had renal involvement. All three developed a preeclamptic syndrome in the third trimester, with deteriorating renal function preceding maternal death. This uniformly fatal outcome, in the opinion of these authors, warrants termination of pregnancy at the first sign of preeclampsia in this disorder.

\section{Renal Biopsy in Pregnancy}

Renal biopsy is an established procedure in the investigation of renal disease, with particular reference to glomerular abnormalities. The technicalities and applications of this procedure are widely documented (Ciba Foundation, 1961; Kark and Buenger, 1966; Brewer, 1973; Kark and Smith, 1974; Burkholder, 1974) and require no further elaboration. Irrespective of pregnancy, renal biopsy carries a small risk to the patient. Kollowitz (1961) noted macroscopic haematuria in $3.73 \%$ and perirenal haematuria in $0.58 \%$ of biopsied patients. Slotkin and Madsen (1962), in a review of 5000 cases throughout the USA, recorded severe complications, mainly as perirenal haematoma, in $0.7 \%$ (necessitating nephrectomy in some instances) and a mortality of $0.1 \%$. As biopsy methods have improved, so have the overall statistics, although occasional unusual complications, including urinary fistula from a damaged renal pelvis, selfhealing arteriovenous fistula and dislodgement of renal medullary calcifications have been reported (River et al, 1970). Pregnancy enhances these hazards on account of the altered anatomical and physiological conditions, particularly in its later stages, and it may be advisable in appropriate cases to delay biopsy until after delivery when risks and technical difficulties are less, although renal structural changes still apply. On this account, and for other reasons, renal biopsy during pregnancy has had a rather limited application, particularly in the United Kingdom.

One of the main contributions of renal biopsy has been the elucidation of the histopathology of the preeclampsia syndrome (Spargo et al, 1959; Altchek, 1961; Mautner et al, 1962), particularly at the glomerular level. Renal biopsies taken at Caesarean section from 66 multiparae with toxaemia or previous history of eclampsia, chronic glomerulonephritis, pyelonephritis, or lupus nephritis as well as from 10 normal multiparae, disclosed the reversibility of the eclamptic changes (Dieckmann et al, 1958). Pollack and Nettles $(1960 \mathrm{a}, \mathrm{b})$ studied biopsies from 50 pregnant patients with hypertension and/or proteinuria and oedema; preeclampsia occurred in 35 cases, vascular disease (arteriosclerosis) in 10 and various primary glomerulopathies in five. Thus, not only were they able to distinguish toxaemic from nontoxaemic patients but they also confirmed the reversibility of the toxaemic renal lesions in all but the most severe cases, This irreversible component, according to Dennis et al (1968) on the basis of their biopsy and clinical experience, was due to a glomerular component of vascular disease. Immunofluorescent studies of biopsy specimens have also disclosed significant fibrin deposition but scanty globulins localized in glomeruli of toxaemic patients, a feature which Morris et al $(1964,1968)$ suggest may be of diagnostic help in equivocal cases.

Biopsy specimens taken during the puerperium from 20 toxaemic patients and from 13 with abruptio 
placentae have been shown to share common histological and electron optical glomerular features (Thomson et al, 1972). On this evidence, the authors regard disseminated intravascular coagulation as the basis of both disorders, promoted by different rates of release of placental thromboplastin.

Renal biopsy also affords a useful, and according to Felding (1968), the only way, of detecting the true nature of disease underlying deterioration of kidney function during pregnancy, and of identifying primary glomerular diseases or preeclamptic changes as possible causés (Marcus, 1963; Kincaid-Smith et al, 1967). It has also contributed to the diagnosis of renal cortical necrosis and in predicting its outcome (Kleinknecht et al, 1973). Attempts at isolation of pathogenic microorganisms from renal biopsy specimens from patients with pyelonephritis (Jacobson and Newman, 1962; Jackson et al, 1957) have been unproductive and of questionable value.

Renal biopsy is firmly established as one of the nephrologist's investigative techniques. Clinical judgment and technical expertise are essential to its application, particularly in pregnancy (Schewitz et $a l, 1965)$. Experience in the interpretation of a range of laboratory procedures, including immunofluorescence of cryostat frozen sections using appropriate fluorescein-labelled antisera and electron as well as conventional light, microscopy, is also essential if its full value in diagnosis, prognosis and research is to be realised.

\section{References}

Altchek, A. (1961). Electron microscopy of renal biopsies in toxemia of pregnancy. J. Amer. med. Ass., 175, 791-795.

Asscher, A. W. (1974). Urinary tract infection. Lancet, 2, 1365-1367.

Baker, S. B., de C. (1958). Intravascular haemopoiesis in the renal medulla in shock. J. Path. Bact., 75, 421-428.

Barnes, C. G. (1970). Medical Disorders in Obstetric Practice, 3rd ed. Blackwell, Oxford.

Berman, L. B. (1974). The pregnant kidney. J. Amer. med. Ass., 230, 111-112.

Blainey, J. D., and Studd, J. W. (1971). Nephritis and pregnancy. Quart. J. med. 40, 566-567.

Brewer, D. B. (1973). Renal Biopsy. 2nd ed. Arnold, London. Brun, C., and Olsen, T. S. (1968). In Structural Basis of Renal Disease, edited by E. L. Becker, pp. 387-400. Hoeber, New York.

Bull, G. M., Joekes, A. M., and Lowe, K. G. (1950). Renal function studies in acute tubular necrosis. Clin. Sci., 9, 379-404.

Bullen, M., and Kincaid-Smith, P. (1971). Asymptomatic pregnancy bacteruria-a follow-up study 4-7 years after delivery. In Renal Infection and Renal Scarring, edited by P. Kincaid-Smith and K. F. Fairley, pp. 33-39. Mercedes Publishing Services, Melbourne.

Burkholder, P. M. (1974). Atlas of Human Glomerular Pathology, p. 1. Harper and Rowe, Hagestown, Maryland.

Burt, R. L., and Kearns, P. R. (1953). Bilateral cortical necrosis of the kidneys. A case report with laboratory and necropsy findings. Obstet. and Gynec., 2, 484-494.

Churg, J., Koffler, D., Paronetto, F., Rorat, E., and Barnett, R. N. (1970). Hemolytic uremic syndrome as a cause of postpartum renal failure. Amer. J. Obstet. Gynec., 108, 253-261.

Ciba $\times 3$ Foundation (1961). Symposium on Renal Biopsy, edited by G. E. W. Wolstenholme and M. P. Cameron. Churchill, London.

Dennis, E. J., McIver, F. A., and Smythe, C. M. (1968). Renal biopsy in pregnancy. Clin. Obstet. Gynec., 11, 473-486.

Devi, P. K., Sutaria, U. D., Asolkar, P., and Deshmukh, M. (1967). Diagnosis of latent urinary tract infections in pregnancy: study of the iron sorbitol citric acid provocative test. Amer. J. Obstet. Gynec., 97, 39-42.

Dieckmann, W. J., McCartney, C. P., and Harrod, J. P., Jr. (1958). Kidney biopsies in multiparous patients with vascular renal disease in pregnancy. Amer. J. Obstet. Gynec., 75, 634-655.

Donaldson, L. B. (1952). Lupus erythematosus in pregnancy. West. J. Surg., 60, 579-584.

Donaldson, L. B., and De Alvarez, R. R. (1962). Further observations on lupus erythematosus associated with pregnancy. Amer. J. Obstet. Gynec., 83, 1461-1473.

Dure-Smith, P. (1968). The female ureter and pyelonephritis. Brit. J. Urol., 40, 415-417.

Ellis, F. A., and Bereston, E. S. (1952). Lupus erythematosus associated with pregnancy and menopause. Arch. Dermat. Syph. (Chic.), 65, 170-176.

Estes, D., and Larson, D. L. (1965). Systemic lupus erythematosus and pregnancy. Clin. Obstet. Gynec., 8, 307-321.

Fairley, K. F. (1971). The routine determination of the site of infection in the investigation of patients with urinary tract infection. In Renal Infection and Renal Scarring, edited by P. Kincaid-Smith and K. F. Fairley, pp. 107-116. Mercedes Publishing Services, Melbourne.

Felding, C. F. (1968). Pregnancy following renal diseases. Clin. Obstet. Gynec., 11, 579-593.

Finkelstein, F. O., Kashgarian, M., and Hayslett, J. P. (1974). Clinical spectrum of postpartum renal failure. Amer. J. Med., 57, 649-645.

Friedman, E. A., and Rutherford, J. W. (1956). Pregnancy and lupus erythematosus. Obstet. and Gynec., 8, 601-610.

Garsenstein, M., Pollak, V. E., and Kark, R. M. (1962). Systemic lupus erythematosus and pregnancy. New Engl. J. Med., 267, 165-169.

Harkins, J. L., Wilson, D. R., and Muggah, H. F. (1974). Acute renal failure in obstetrics. Amer. J. Obstet. Gynec., 118, 331-336.

Haslam, A. J., and Wallace, M. R. (1975). The transient nephrotic syndrome of pregnancy. N.Z. med. J., 81, 470-472.

Jackson, G. G., Poirier, K. P., and Grieble, H. G. (1957). Concepts of pyelonephritis: experience with renal biopsies and long-term clinical observations. Ann. intern. Med., 47, $1165-1183$.

Jacobson, M. H., and Newman, W. (1962). Study of pyelonephritis using renal biopsy material. Arch. intern. Med., 110, 211-217.

Jewett, J. F. (1972). Disseminated lupus erythematosus. New Engl. J. Med., 287, 1199-1200.

Johnston, C. I., Johnson, J. R., and Reader, R. (1963). The nephrotic syndrome in pregnancy. Aust. Ann. Med., 12, 342-345.

Kaitz, A. L. (1961). Urinary concentrating ability in pregnant women with asymptomatic bacteriuria. J. clin. Invest., 40, 1331-1338.

Kark, R. M., and Buenger, R. E. (1966). Television-monitored fluoroscopy in percutaneous renal biopsy. Lancet, 1, 904905. 
Kark, R. M., and Smith, R. D. (1974). Renal biopsy. Advanc. intern. Med., 19, 363-390.

Karlen, J. R., and Cook, W. A. (1974). Renal scleroderma and pregnancy. Obstet. and Gynec., 44, 349-354.

Kass, E. H. (1960). Bacteriuria and pyelonephritis of pregnancy. Arch. intern. Med., 105, 194-198.

Katz, Y. J., Velasquez, A., and Bourdo, S. R. (1962). The prednisolone provocative test for pyelonephritis. Lancet, 1 , 1144-1145.

Kincaid-Smith, P. (1968). Bacteriuria and urinary infection in pregnancy. Clin. Obstet. Gynec., 11, 533-549.

Kincaid-Smith, P., Fairley, K. F., and Bullen, M. (1967). Kidney disease and pregnancy. Med.J. Aust., 2, 1155-1159.

Kleeman, C. R., Hewitt, W. L., and Guze, L. B. (1960). Pyelonephritis. Medicine (Baltimore), 39, 3-116.

Kleinknecht, D., Grünfeld, J. P., Gomez, P. C., Moreau, J. F., and Garcia-Torres, R. (1973). Diagnostic procedures and long-term prognosis in bilateral renal cortical necrosis. Kidney Int., 4, 390-400.

Klempner, E., Oppenheimer, G. D., and Glickman, S. I. (1960). Urological complications. In Medical, Surgical and Gyneacological Complications of Pregnancy, edited by A. E. Guttmacher and J. J. Rovinsky, pp. 255-265. Baillière, Tindall, and Cox, London.

Kollwitz, A. A. (1961). Eine Ubersicht über 5700 perkutane Nierenbiopsien. Med. Klin., 56, 726-731.

Little, P. J., and De Wardener, H. E. (1962). The use of prednisolone phosphate in the diagnosis of pyelonephritis in man. Lancet, 1, 1145-1149.

Loughbridge, L. W., Milne, M. D., Shackman, R., and Wootton, I. D. P. (1960). Clinical course of uncomplicated acute tubular necrosis. Lancet, 1, 351-355.

Lowe, K. G. (1952). The late prognosis in acute tubular necrosis. Lancet, 1, 1086-1088.

Luke, R. G., Talbert, W., Siegel, R. R., and Holland, N. (1970). Heparin treatment for post-partum renal failure with microangiopathic haemolytic anaemia. Lancet, 2, 750-753.

Massachusetts General Hospital (1973). Case records 21973. New Engl. J. Med., 288, 93-99.

McGee, C. D., and Makowski, E. L. (1970). Systemic lupus erythematosus in pregnancy. Amer. J. Obstet. Gynec., 107, 1008-1012.

McKay, D. G., Merrill, S. J., Weiner, A. E., Hertig, A. T., and Reid, D. E. (1953). The pathologic anatomy of eclampsia, bilateral renal cortical necrosis, pituitary necrosis, and other acute fatal complications of pregnancy, and its possible relationship to the generalized Schwartzman phenomenon. Amer. J. Obstet. Gynec., 66, 507-539.

Marcus, S. L. (1963). The nephrotic syndrome during pregnancy. Obstet. Gynec. Surv., 18, 511-542.

Mautner, W., Churg, J., Grishman, E., and Dachs, S. (1962). Pre-eclamptic nephropathy; an electron microscopic study. Lab. Invest., 11, 518-530.

Morris, R. H., Vassalli, P., Beller, F. K., and McCluskey, R. T. (1964). Immunofluorescent studies of renal biopsies in the diagnosis of toxemia of pregnancy. Obstet. and Gynec., 24, 32-46.

Morris, R. H., Vassalli, P., and McCluckey, R. T. (1968). Immunofluorescent studies on renal biopsies in pregnancy. Clin. Obstet. Gynec., 11, 522-532.

Murray-Jones, J. (1954). Acute post-partum renal failure (lower nephron nephrosis), with a report of two unusual cases. Med. J. Aust., 2, 179-181.

Nilsson, I. M., and Kullander, S. (1967). Coagulation and fibrinolytic studies during pregnancy. Acta obstet. gynaec. scand., 46, 273-303.

Norden, C. W., and Tuttle, E. P. J. (1965). In Progress in Pyelonephritis, edited by E. H. Kass, pp. 73-80. Davis, Philadelphia.
Ober, W. E., Reid, D. E., Romney, S. L., and Merrill, J. P. (1956). Renal lesions and acute renal failure in pregnancy. Amer. J. Med., 21, 781-810.

Oliver, J., MacDowell, M., and Tracy, A. (1951). The pathogenesis of acute renal failure associated with traumatic and toxic injury: Renal ischemia, nephrotoxic damage and the ischemuric episode. J. clin. Invest., 30, 1307-1351.

Pinkerton, J. H. M., Wood, C., Williams, E. R., and Calman, R. M. (1961). Sequelae of urinary infection in pregnancy: a five-year follow up. Brit. med. J., 2, 539-542.

Pollak, V. E., and Nettles, J. B. (1960a). Preliminary observations on the differential diagnosis of toxemias of pregnancy by means of renal biopsy. Amer. J. Obstet. Gynec., 79, 866-870.

Pollak, V. E., and Nettles, J. B. (1960b). The kidney in toxemia of pregnancy: a clinical and pathological study based on renal biopsies. Medicine (Baltimore), 39, 469-526.

River, G. L., Dovenbarger, W. V., Nikolai, T. F., and Moffat, N. A. (1970). Unusual complications of kidney biopsy. J. Urol., 103, 15-17.

Rizza, C. R. (1970). In Scientific Foundations of Obstetrics and Gynecology, edited by E. E. Philipp, J. Barnes, and M. Newton, p. 323. Davis, Philadelphia. Heinemann, London.

Robson, J. S., Martin, A. M., Ruckley, V. A., and MacDonald, M. K. (1968). Irreversible post-partum renal failure: a new syndrome. Quart. J. Med., 37, 423-435.

Rosenmann, E., Kanter, A., Bacani, R. A., Pirani, C. L., and Pollak, V. E. (1969). Fatal late postpartum intravascular coagulation with acute renal failure. Amer. J. med. Sci., 257, 259-273.

Schewitz, L. J., Friedman, I. A., and Pollak, V. E. (1965). Bleeding after renal biopsy in pregnancy. Obstet. and Gynec., 26, 295-304.

Schreiner, G. E. (1963). The Nephrotic Syrdome In Diseases of the Kidney, 1 st ed., edited by M. B. Strauss and L. G. Welt, p. 389. Little, Brown, Boston.

Sharon, E., Jones, J., Diamond, H., and Kaplan. D. (1974). Pregnancy and azothioprine in systemic lupus erythematosus. Amer. J. Obstet. Gynec., 118, 25-28.

Sheehan, H. L., and Moore, H. C. (1952). Renal Cortical Necrosis and the Kidney of Concealed Accidental Haemorrhage, Blackwell, Oxford.

Sims, E. A. H. (1968). Renal function in normal pregnancy. Clin. Obstet. Gynec., 11, 461-472.

Slotkin, E. A., and Madsen, P. O. (1962). Complications of renal biopsy: incidence in 5000 reported cases. J. Urol., 87, 13-15.

Spargo, B. H., McCartney, C. P., and Winemiller, R. (1959). Glomerular capillary endotheliosis in toxemia of pregnancy. Arch. Path., 68, 593-599.

Straub, P. W., Von Felten, A., and Frick, P. G. (1966). Recurrent intravascular coagulation with renal cortica necrosis and recovery. Ann. intern. Med., 64, 643-654.

Strauch, B. S., and Hayslett, J. P. (1974). Kidney disease and pregnancy. Brit. med. J., 4, 578-582.

Studd, J. W. W. (1973). The origin and effects of proteinuria in pregnancy. J. Obstet. Gynaec. Brit. Cwlth, 80, 872-883.

Studd, J. W. W., and Blainey, J. D. (1969). Pregnancy and the nephrotic syndrome. Brit. med. J., 1, 276-280.

Thomson, D., Paterson, W. G., Smart, G. E., MacDonald, M. K., and Robson, J. S. (1972). The renal lesions of toxaemia and abruptio placentae studied by light and electron microscopy. J. Obstet. Gynaec. Brit. Cwlth, 79, 311-320.

Tillman, A. J. B. (1951). Toxemias of pregnancy. Med. Clin. N. Amer., 35, 677-698.

Wagoner, R. D., Holley, K. E., and Johnson, W. J. (1968). Accelerated nephrosclerosis and postpartum acute renal 
failure in normotensive patients. Ann. intern. Med., 69, 237-248.

Weisman, S. A., Simon, N. M., Herdson, P. B., and Franklin, W. A. (1973). Nephrotic syndrome in pregnancy. Amer. $J$. Obstet. Gynec., 117, 867-883.

Wells, J. D., Marolin, E. G., and Gall, E. A. (1960). Renal cortical necrosis. Clinical and pathologic features in twenty-one cases. Amer. J. Med., 29, 257-267.

Whalley, P. (1967). Bacteriuria of pregnancy. Amer. J.
Obstet. Gynec., 97, 723-738.

Williams, G., and Hughes, M. (1974). Post-partum renal failure. J. Path., 114, 149-154.

Woods, J. W., and Williams, T. F. (1971). Hypertension due to renal vascular disease, renal infarction, and renal cortical necrosis. In Diseases of the Kidney, 2nd ed., edited by M. B. Strauss and L. G. Welt, Vol. 2, p. 769. Little, Brown, Boston. 